Revista General de Información y Documentación ISSN: 1132-1873

http://dx.doi.org/10.5209/rgid.72814

\title{
La Guerra Civil Española en Crónica (1929-1938) durante el primer año de contienda. Poética fotográfica como información y estrategia
}

\author{
Beatriz de las Heras Herrero ${ }^{1}$
}

Recibido: 31 de agosto de 2020 / Aceptado: 4 de noviembre de 2020

Resumen. Para conseguir que la fotografía se convierta en fuente de análisis del pasado, es imprescindible trascender la faceta ilustrativa de lo visual. No es lo mismo reconocer motivos que interpretar imágenes. Interpretar obliga al lector visual a trascender la vista y proyectar la mirada, y este es el objetivo final del artículo. La proyección se hará sobre una colección concreta: las fotografías publicadas en el semario Crónica (1929-1938) desde julio hasta diciembre de 1936, coincidiendo con los seis primeros meses de la Guerra Civil Española. Y lo haremos con un método basado en tres fases: primero, catalogar, de forma individualizada, cada una de las 931 fotografías que coparon las páginas de la publicación en el periodo de estudio. Segundo, crear perfiles porcentuales basados en el resultado cuantitativo, con la intención de descubrir una tendencia. Tercero, interpretar este resultado para registrar aquellos comportamientos camuflados que nos permitan extraer una información que está en la propia instantánea pero se presenta como velada si aplicamos una mirada distraída.

Palabras clave: Fotografía; Guerra Civil Española; Memoria; Estrategia de comunicación; Método cuantitativo; Interpretación visual.

\section{[en] The Spanish Civil War in Crónica (1929-1938) during the first year of the battle. The poetic photography as information and strategy}

\begin{abstract}
To make photography become a source of analysis of the past, it is necessary to transcend the illustrative facet of the visual. Recognising reasons and interpreting images are not the same thing. Interpreting forces the visual reader to transcend the sight and project the glance, and this is the ultimate aim of the article. The projection will be taken from a specific collection: The photographs published in the weekly publication Chronicle (1929-1938) from July to December 1936, coinciding with the first six months of the Spanish Civil War. And we will use a methodology based on three phases: the first one consists of cataloguing individually each of the 931 photographs which covered the pages of the publication during the period of study. The second one is the creation of percentage profiles based on the quantitative results with the intention of discovering a trend. The third phase is the interpretation of this result with the intention of recording those camouflaged performances which allow us to extract information included in the snapshot but which is blurred if we apply a distracted gaze. Therefore, our aim is to launch a curious look on the photographs published in Chronicle between July and December 1936.

Keywords: Photography; Spanish Civil War; Memory; Strategy; Quantitative Method; Visual interpretation.
\end{abstract}

1 Instituto de Cultura y Tecnología. Universidad Carlos III de Madrid

E-mail: bheras@hum.uc3m.es 
Sumario. 1. Introducción. 2. Crónica, altavoz visual de España (1929-1938). 3. Análisis cuantitativo: Crónica, 1936. 4. La poética visual de Crónica. Información y estrategia. 5. Conclusiones. 6. Referencias bibliográficas.

Cómo citar: Heras Herrero, B. de las (2020) La Guerra Civil Española en Crónica (1929-1938) durante el primer año de contienda. Poética fotográfica como información y estrategia, en Revista General de Información y Documentación 30 (2), 609-629.

\section{Introducción}

La Guerra Civil Española, eje vertebrador de la historia contemporánea del país, se ha convertido en un periodo de inagotable inspiración para los estudiosos de la fotografía. Varios factores coinciden para que esto sea así. El primero, la actual consideración como fuente primaria de información. El hecho de que hoy no se la juzgue como una mera ilustración y sea analizada desde una perspectiva transdisciplinar en la que la Antropología, Sociología, Historia del Arte, Historia, Psicología de la percepción, Comunicación o Documentación se conectan para poder afrontar el fenómeno complejo que se produce con la toma de una instantánea, ha ayudado a una activación por su interés. Además, en el caso del periodo 1936-1939, coinciden otros aspectos: la gran producción visual, el seguimiento internacional de la contienda, la mejora de la tecnología fotografía, la proliferación de revistas gráficas, la complejidad de un siglo que ya había dado muestras de la necesidad de contar con la propaganda visual como estrategia, y un público demandante de esa "realidad" que no podía vivir más que por el retrato de un instante, se conjugaron para que la fotografía se convirtiera en un arma de la guerra.

Las miles de instantáneas que recogen el espacio y tiempo de sucesos y acontecimientos del frente y la retaguardia inundan los archivos, álbumes familiares, cajas metálicas repletas de recuerdos y espacios por descubrir en rincones de todo el planeta (Salvador Benítez, 2018). Y este acervo, con gran valor patrimonial e histórico, parece inagotable a tenor de los descubrimientos que, cada año, nos sorprenden. Entre los más recientes, la colección de 5.000 fotografías de Antoni Campañá que apareció en un garaje construido en Sant Cugat de Barcelona en los años 40 (González Villalta, 2019) o los negativos de la fotógrafa Margaret Michaelis tomadas para el Comissariat de Propaganda de la Generalitat de Catalunya, conservadas en el International Institute of Social History (IISH) de Ámsterdam y descubiertos por la historiadora Almudena Rubio, que ya había rastreado, en el mismo fondo, 514 negativos de la fotógrafa Kati Horna (Rubido Pérez, 2020).

También localizamos una fuente inagotable en las páginas de la prensa de hace 80 años, canal difusor de la (re)presentación de la victoria y la derrota, la supervivencia y la muerte, la alegría y el dolor. Entre las revistas españolas encontramos las ya conocidas durante la Segunda República (Estampa, Blanco y Negro, o Mundo Gráfico) y otras creadas durante la contienda como Fotos, Destino o Revista, al margen de los diarios habituales que incorporaron a sus páginas un gran despliegue fotográfico, como $A B C$, para cubrir las noticias que llegaban del frente y la retaguardia, contando con profesionales de la talla de Alfonso, P. Luis Torrents, 
Centelles, Albero y Segovia, los hermanos Mayo, José María Casariego o Santos Yubero, entre los reporteros que cubrieron a los antifascistas, o Serrano, Campúa, Compte, Calvache, Contreras Saldaña, Zegrí o Cortés Faure, por destacar algunos nombres (De las Heras, 2017).

El objetivo del artículo es recuperar una parte de esa historia a través de la narración visual. Y hacerlo, además, en su esencia, es decir, intentando una aproximación a su significado en el contexto original: el del lector primero. ¿Cómo? A través de la prensa de la época. La proliferación de diarios y semanarios en los años 30 hace que tengamos muchas opciones para emprender ese estudio. De entre todas, optamos por Crónica. ¿La razón? Fue una revista gráfica en la que el elemento fotográfico estuvo muy presente y lo hizo desde una perspectiva especial: su carácter artístico incluso en un momento tan convulso como la guerra. En su naturaleza estuvo, desde el origen, el modernizar el periodismo gráfico del país y, a pesar de las difíciles circunstancias, lo mantuvo. ¿En qué periodo? Analizaremos la colección del año 1936 por ser el de más posibilidades para los fotógrafos. La ausencia de suministros -algo que les obligó a desempolvar sus viejas cámaras de placas-, la falta de papel y tintas en las rotativas desde el otoño, y el propio ritmo bélico que fue concentrando el interés de las autoridades republicanas en la guerra en primera línea y en la búsqueda del aliado externo más que en la propaganda, sobre todo a partir de la primavera de 1937, convierten los seis primeros meses de contienda en época gloriosa del reporterismo de guerra.

Para el estudio hemos accedido al fondo a través de los números de Crónica correspondientes que se conservan, en un estado magnífico, en la Biblioteca Nacional de España. Después, hemos tratado las más de 900 instantáneas como si fueran parte de un hallazgo arqueológico ${ }^{2}$. Cada fotografía es una pieza que se localiza, se rescata, se limpia de los posibles restos que impiden al estudioso apreciar el documento, se determinan sus elementos constitutivos y se detectan informaciones que en él se contienen, para, finalmente, engarzarlos con otras teselas de información que nos permitan reconstruir ese pasado a modo de mosaico. Hablamos de Arqueología porque se trabaja con fragmentos de tiempo, porque se estudia cada uno de ellos para su identificación (determinando el tiempo o momento de registro, el espacio o lugar, los elementos que contiene y el autor del trabajo) y porque se relacionan con la intención de reconstruir un lugar, un suceso, un acontecimiento (De las Heras, 2011).

Las fases de trabajo son tres. Primero, realizamos una catalogación individualizada de cada una de las piezas en las que se ha identificado la fecha de publicación, la situación de la fotografía en el periódico, la autoría y un resumen del asunto para, finalmente, asignar un descriptor teniendo en cuenta tres cuestiones: el espacio virtual en la que se tomó -diferenciando frente, retaguardia y retaguardia militar-, el espacio geográfico (población o región) y el tema. En segundo lugar, creamos unos perfiles teniendo en cuenta el número de instantáneas, el periodo de

2 Michel Foucault (1970: 171-172) formuló un método arqueológico aplicado a fenómenos del discurso y el profesor Antonio Rodríguez de las Heras (1947-2020) lo trasladó al fenómeno de la representación, punto de partida de nuestra metodología de análisis (Rodríguez de las Heras, 2010). 
publicación, la autoría y los temas retratados con la intención de descubrir una tendencia que aporte más información sobre el contexto. El resultado de este trabajo es cuantitativo. Nos indica, numéricamente, el grado de atención de los distintos temas en diferentes momentos y el resultado, apoyado en datos objetivos, se convierte en el pilar que explica distintas estrategias de comunicación visual durante el conflicto. Finalmente, y como tercera etapa, la interpretación fundamentada en los datos y en el análisis integral de cada instantánea. El método está basado en una observación controlada de un conjunto de fotografías -en este caso las publicadas en Crónica durante los seis primeros meses de guerra- con la intención de registrar aquellos comportamientos camuflados que nos permitan extraer una información que está en la propia instantánea pero se presenta como velada si aplicamos un análisis abstraído. Nuestra finalidad es, por tanto, lanzar una mirada reflexiva a las fotografías publicadas en Crónica entre julio y diciembre de 1936.

\section{Crónica, altavoz visual de España (1929-1938)}

Crónica fue una revista gráfica semanal editada por Prensa Gráfica y publicada, desde su sede en el número 17 de la calle Hermosilla de Madrid, en España los domingos desde 1929 y hasta el 11 de diciembre de 1938. Su inicio coincidió con el momento de auge de la prensa gráfica española gracias al desarrollo de la tecnología fotográfica, la consolidación del fotograbado -que permitió reproducir originales mediante una fotografía- y del huecograbado -que mejoró las reproducciones sobre papel-, al margen de la mayor calidad de tintas y papel.

Tuvo un marcado carácter liberal, republicano y con gran aperturismo moral. Su vida corrió en paralelo a la de Estampa (1928-1938), más conservadora, de la que fue competidora desde su primer número hasta el último. Las dos publicaciones siguieron la estela de las consagradas Nuevo Mundo (1894-1933), Mundo Gráfico (1911-1938) y La Esfera (1914-1931), y rivalizaron con Blanco y Negro (18912000), también, de Prensa Española.

Editada en tamaño tabloide y formato 38 x $28 \mathrm{~cm}$., su tirada fue de 200.000 ejemplares y se distribuyó en todas las provincias y colonias españolas, además de contar con suscripciones en Francia, Alemania, Portugal y algunos países latinoamericanos. Su número de páginas inicial fue de 16 aunque se amplió a 24 y 40 hasta que empezó a reducirse en el periodo de la guerra: de las 40 páginas en el número del 19 de julio de 1936 hasta las 8 páginas del número del 11 de diciembre de 1938, última revista. Su precio inicial fue de 20 céntimos aunque terminó costando 40 céntimos desde el 20 de junio de 1937, durante el segundo año de guerra. Su estilo recuerda a los magazines franceses, consecuencia de que fuera dirigida en su inicio por el periodista Antonio González Linares, corresponsal español en Paris y que había llevado la dirección de Estampa.

Si en algo destacó el semanal fue en la modernidad de sus números que abrieron el camino a la vanguardia: "Desde 1928 y 1929, respectivamente, los semanarios gráficos Estampa y Crónica supusieron la introducción del formato francés y alemán, al modo de Vu, Paris Soir o Berliner Illustreiter -preferencia de la fotografía 
obre lo literario, composición más límpida y atrevida, abandono de las grecas de inspiración modernista, por titulares a la moda art decó -en un modo que habían dominado las ya declinantes fórmulas de La Esfera y Mundo Gráfico" (Mainer, 2006: 456). Los números se imprimieron en huecograbado color sepia, con un seguimiento a través de crónicas y reportajes de actualidad de Madrid, provincias y extranjero. Lo visual fue fundamental desde el origen de Crónica, ya que se imprimió un gran número de fotografías -al margen de dibujos y otras representaciones gráficas-, incluso dando protagonismo central al publicarse a toda página en portada e interior. En el inicio se abrió con " 50 fotos reproducidas en formatos grandes, sobre todo en portada y contraportada, donde se reprodujeron habitualmente a página" (Vigil y Olivera, 2014: 40), número de instantáneas que creció al aumentar el de páginas. Entre los fotógrafos más reconocidos identificamos a Campúa, responsable de reportajes antes de la guerra, Del Río, reportero que cubrió el mundo del arte, y Álvaro responsable de inmortalizar las noticias deportivas. A este equipo se sumó Torrents, Gaspar y Merletti en Barcelona, Gil de Espinar en Bilbao, Calle en Huelva, Quintana en Santander, Sánchez del Pando y Serrano en Sevilla y Desfilis en Valencia, además de Alfonso, Sacedón, Piortiz, M. Cortés, Vicente López Videa, Díaz Casariego, Baldomero hijo, Rodero, o RASM, además de los dibujantes: Penagos, Ribas, Pitti Bartolozzi, Delhi Tejero, Robledano, Echea, Sirio, José Zamora o Demetrio (Vigil y Olivera, 2014).

Si nos centramos en el periodo bélico, la revista fue, como todos los medios de comunicación, colectivizada por sus trabajadores y quedó dirigida por la autoridad política de la ciudad. Toda publicación gráfica, incluidos los semanarios como Crónica, debía someterse a la censura y los fotógrafos tenían que presentar tres copias de sus instantáneas. La primera, si se autorizaba, se devolvía al reportero, y dos se conservaban en la Delegación para, según se aclara en la disposición aprobada por la Delegación de Propaganda y Prensa de la Junta Delegada de Defensa de Madrid: "constituir el Archivo de la revolución que en su día será depositado donde disponga el Gobierno legítimo de la República”. Además, el fotógrafo también estuvo controlado ya que debía solicitar una autorización para fotografiar en la retaguardia y para el frente necesitaban, además, que el permiso expedido estuviera acompañado de la autorización de los jefes militares de los respectivos sectores. Estas licencias debían ser mostradas junto al carnet de la Delegación de Propaganda y Prensa de la Junta o la Junta Delegada, si eran requeridas. Algo que fue constante y objeto de interés de los propios reporteros que lo fotografiaron en distintas ocasiones. Ejemplo es esta instantánea del fotógrafo Montaña (Figura 1) que retrata el instante preciso en el que una miliciana le solicitó el permiso, fotografía que fue publicada en Crónica el 20 de septiembre de 1936. 


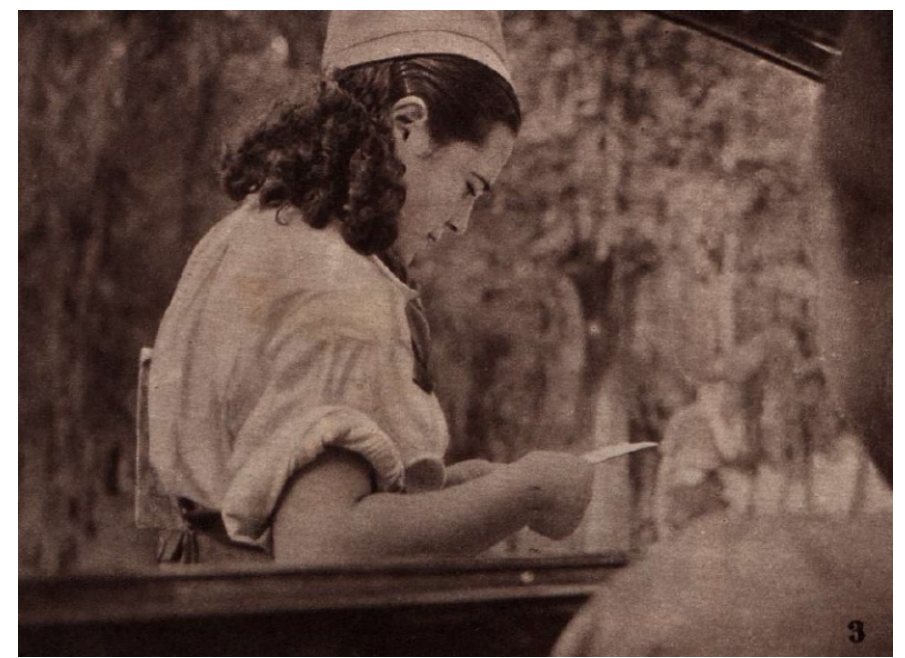

Figura 1. Fotografía de Montaña en Crónica. Madrid, 20 de septiembre de 1936

No hay que olvidar, además, que los responsables militares también se encargaron de organizar el desplazamiento colectivo de reporteros en coches en cuyo parabrisas se especificaba que era un "vehículo de control". A pesar de las precauciones que tomaron las autoridades, los fotógrafos y cronistas sufrieron las consecuencias directas del conflicto en los desplazamientos para cubrir el frente y la retaguardia. Como narró Vicente Videa, reportero de prensa gráfica que desde los primeros días de la contienda cubrió la sublevación en la sierra de Madrid para Crónica y Mundo Gráfico. Ante la pregunta de un periodista de La Voz -que publicó un reportaje el 5 de diciembre de 1937- sobre los peligros de la guerra, y al margen de dejar patente cómo siempre estaba acompañado por guardias de asalto para tomar sus fotos en primera línea, reflexionó sobre la exposición a muchos peligros: “Más de una vez tuvimos que refugiarnos entre dos balcones porque una lluvia de balas entraba por los huecos y se clavaban en la pared frontera”. Pero se daban situaciones todavía más graves: la muerte de periodistas y fotógrafos. Por ejemplo, la de Manuel Fernández Alvar, acribillado en Guadarrama el 23 de julio cuando cubría la guerra para el Heraldo de Madrid, según narró Crónica el 9 de agosto de 1936. La noticia se acompañó de dos instantáneas del fotógrafo Cervera en las que se retrata un grupo de milicianos observando el vehículo en el que murió el periodista. Entre los fotógrafos que fallecieron Campúa, director de Mundo Gráfico (ejecutado en la checa de Fomento el 22 de septiembre de 1936), Julio Duque, fotógrafo de $A B C$, o el retratista Walken. A estos se sumaron, avanzada la contienda, otros, como Germán Yusti que, colaborando para $A B C$, falleció en el mes de abril de 1937. También corresponsales extranjeros como la fotógrafa Gerda Taro, que trabajó para las revistas francesas Ce Soir y Regards y que murió, como consecuencia de un accidente, en el frente de Brunete el 25 de julio de 1937, o los reporteros Bradish Johson y Edward J. Neil - de Newsweek y la agencia Associated Press (A.P.), respectivamente- que fallecieron en el pueblo de Caudé el 31 de diciembre de 1937 cuando su vehículo fue atacado por la artillería antifascista mientras se dirigían a 
cubrir la batalla en los alrededores de Teruel, tras la convocatoria de los responsables de prensa del gobierno sublevado (Aupí, 2017). Noticia que dio la vuelta al mundo gracias a la publicación de las fotografías de Associated Press en en The New York Times el 12 de enero de 1938.

Al margen del control, la censura y los peligros de trabajar bajo la metralla y las bombas, los reporteros que trabajaron para Crónica tuvieron que enfrentarse al problema de los suministros que afectó a la prensa en general. La reducción de las páginas de revistas y periódicos fue aprobada, por primera vez, por la Junta de Defensa de Madrid el 10 de noviembre de 1936, y se mantuvo hasta el final de la contienda. Esta decisión provocó las quejas de los responsables, como se hizo en un acto inter-sindical celebrado en Madrid en el que Miguel San Andrés, director del diario Política, recordaba que, tal y como se recogió en el $A B C$ del 10 de mayo de 1938: “(...) los periódicos necesitan papel y necesitan que se unifiquen los precios de venta de ejemplares”. Además, los fotógrafos tuvieron un problema añadido: el de la falta de suministros propios: "La ausencia de negativos de paso universal llevó a muchos de ellos- a los fotógrafos- a recuperar sus cámaras de placas y a utilizar restos de películas de los noticieros cinematográficos. Alfonso debió recurrir a sus viejas cámaras estereoscópicas para realizar un reportaje, encargado por el Ayuntamiento, sobre los estragos producidos por los bombardeos en las calles de Madrid” (López Mondéjar, 2005: 89). En momentos puntuales, los fotógrafos que trabajaron en Madrid, por ejemplo, recibieron suministros soviéticos, como el papel, pero de muy mala calidad, tal y como confesó Julio Mayo al fotohistoriador Publio López Mondéjar: "pues con el calor le salían ampollas, desprendiéndose la emulsión del soporte” (2005: 309). Además, tuvieron que enfrentarse al atraso de los pagos o su sustitución por vales emitidos por partidos y sindicatos. Sobre lo que cobraron los reporteros no se conoce demasiado. 300 pesetas de media mensual para los 34 reporteros gráficos en plantilla y que estaban adscritos a la Agrupació Professional de Periodistas de Barcelona, controlada por U.G.T. con el inicio del conflicto, y 5 pesetas por cada instantánea publicada por los colaboradores (Vigil y Olivera, 2014: 261). En el lado sublevado conocemos, gracias a un llamamiento publicado en $A B C$, edición Sevilla, el 29 de enero de 1938, que se pagó entre 20 y 15 pesetas por imagen publicada en portada: "Por ello solicita la colaboración de los fotógrafos españoles, que percibirán quince pesetas por las "fotos" de escenas de los frentes y diez pesetas por las que representen actos celebrados en la retaguardia, siendo remuneradas las que se publiquen en la portada a 20 y 15 pesetas, respectivamente".

Ante este y otros problemas, algunos profesionales decidieron fusionarse para sobrellevar las dificultades que imponía la guerra: la unión en agencia, como ocurrió con los hermanos Benítez Casaux (Alberto y César Benítez Alcoba) y Santos Yubero, fotógrafos quienes retomaron la agencia Yubero-Benítez Casaux que colaboró con ABC, Crónica, La Libertad, Ahora, Estampa, Mundo Gráfico y Crónica, al margen de los reportajes que distribuyeron de y en la prensa extranjera. También se sospecha que, sin formalizar, era habitual la colaboración de otros fotógrafos, como, por ejemplo, Joan Puig Farran, Torrents y Centelles en Cataluña, ya que se han localizado copias firmadas por los dos primeros en el Archivo Centelles. Además, parece común en la época la permuta entre profesionales de la 
fotografía, aunque este es uno de esos episodios que, aún 80 años después de la guerra, están sin estudiar.

\section{Análisis cuantitativo: Crónica, 1936}

Si centramos nuestra atención en el primer número de Crónica tras la sublevación, el del 19 de julio de 1936, no recogió, como es lógico por tener el ejemplar cerrado antes del golpe, la noticia del suceso. La portada fue para una fotografía de R.K.O con un primer plano de la actriz estadounidense Ginger Rogers. Aunque se incorporó una referencia al clima de tensión en el artículo "Los abominables asesinatos del teniente de Asalto don José Castillo y del diputado y líder derechista don José Calvo Sotelo”, no es hasta el número del 26 de julio de 1936 cuando Crónica informa. Y lo hace desde la portada (Figura 2), que dedica a dos fotografías de Foto Albero y Segovia en las que se retrata la toma de Guadalajara: la primera, artilleros. La segunda, guardias civiles y milicianos disparando al enemigo.

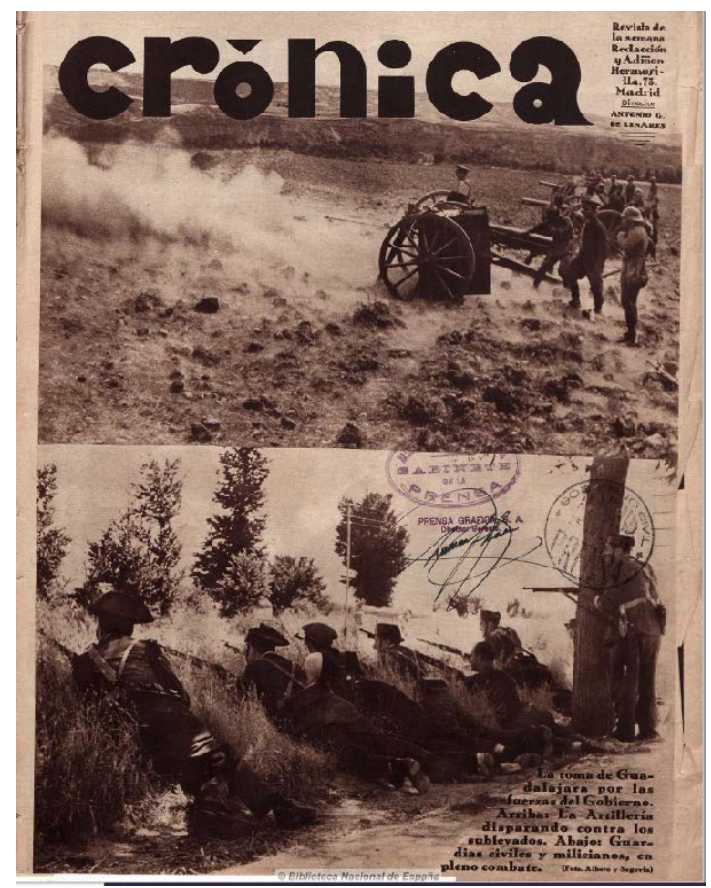

Figura 2. Fotografías de Albero y Segovia en Crónica. Guadalajara, 26 de julio de 1936

En total, fueron 50 las fotografías publicadas en este número, de entre las que 47 están tomadas en Madrid y 3 en Toledo. Todas muestran escenas capturadas en el frente o en la retaguardia militar y sólo una de ellas a civiles -aunque vinculada a la temática militar, concretamente una instantánea en la que hombres y mujeres del pueblo de Fuencarral despiden a las milicias que van a luchar contra los alzados en Somosierra. La mayoría de las instantáneas está identificada, excepto 2 anónimas. 
El resto, son trabajos de Albero y Segovia (30 instantáneas), Fotos Videa (11 instantáneas), Fotos Videa y Piortiz (4 instantáneas), y Fotos Piortiz (3 instantáneas). Parece, además, que el retrato de mujeres participando en primera línea-ya sea como milicianas o como miembros de las patrullas de vigilancia- fue de interés ya que el periódico escogió un reportaje de 2 páginas (“Las mujeres en la lucha”) ilustradas con 6 fotografías: 5 firmadas por Videa y 1 por Albero y Segovia. Interés que se mantuvo, ya que el número siguiente -el correspondiente al 2 de agosto de 1936llevó a su portada la fotografía de una miliciana armada. Se trata de un nuevo retrato de Videa que se acompaña del pie: "Una miliciana de las muchas que combaten o prestan servicios auxiliares, con bravura y abnegación ejemplares”. Esta fotografía forma parte de otras 6 de Videa que se incorporan al artículo.

Vistas algunas particularidades de las primeras instantáneas publicadas en la revista, es el momento de iniciar el análisis exhaustivo de la colección durante el primer año de guerra.

A pesar de los cambios por los que atravesaba España y la propia revista, la esencia de Crónica se mantuvo en los 125 números publicados durante el periodo de guerra. El primero, el 19 de julio de 1936 (Núm. 349). El último, el 11 de diciembre de 1938 (Núm. 474). Aunque sí fue materialmente visible el transcurso del acontecimiento, no sólo por la cobertura puntual de los sucesos protagonistas en el frente y la retaguardia. También, porque la falta de suministros se tradujo en un descenso de las páginas por los problemas de papel y tinta que tuvo que afrontar la prensa de la zona antifascista desde el otoño-invierno de 1936, como ya hemos comentado. Si centramos nuestro análisis en las instantáneas que se publicaron en el periodo de estudio (julio-diciembre de 1936) en los 24 números (del Núm. 349 al Núm. 372), fueron 931 las fotografías que retrataron la guerra desde los tres espacios que se abrieron, como brecha, tras la sublevación militar: el frente, retaguardia militar -espacio de la retaguardia que queda ocupado, puntualmente, por lo militar (por ejemplo, desfiles y actos militares, paso de tropa, descanso de soldados en su marcha a la primera línea, etc.), y la retaguardia. La media de publicación fue de 40 fotografías por número, con un mínimo de 22 instantáneas el 15 de octubre de 1936 y un máximo de 56 el 13 de septiembre de 1936 (Tabla 1).

Si analizamos la cubertura mensual, la mayor intensidad se aprecia en los meses de agosto, septiembre y noviembre -con 201,198 y 199 instantáneas, respectivamente-, mientras que julio (Crónica sólo dedicó dos números) y octubre con 51 y 136 instantáneas, respectivamente, fueron los meses en los que menos espacio visual se dedicó a la guerra. Por tanto, el número de fotografías no depende del de páginas. Un caso particular, en este sentido, es de los números del 18 de octubre y del 22 de noviembre, cuando en sus 15 páginas se publicaron 45 instantáneas. De hecho, y a tenor de los datos comparativos entre páginas e instantáneas, desde el número del 11 de noviembre, primero tras la aprobación de la reducción de papel en revistas y periódicos por parte de la Junta de Defensa de Madrid un día antes, hasta el último número del año 1936, se publicaron 434 fotografías en un total de 188 páginas. Por el contrario, desde el inicio de la guerra y hasta el 10 de noviembre se publicaron 497 instantáneas en 324 páginas, es decir, casi el mismo número de fotografías en el doble de papel (Gráfico 1). 
Tabla 1. Elaboración propia. Fotografías publicadas por número de ejemplar

\begin{tabular}{|c|c|c|}
\hline Núm. Del ejemplar & Núm. De pgnas. & Núm. De fotos \\
\hline 349 & 40 & 0 \\
\hline 350 & 38 & 51 \\
\hline 351 & 32 & 51 \\
\hline 352 & 24 & 43 \\
\hline 353 & 23 & 40 \\
\hline 354 & 24 & 30 \\
\hline 355 & 24 & 37 \\
\hline 356 & 23 & 49 \\
\hline 357 & 24 & 56 \\
\hline 358 & 24 & 50 \\
\hline 359 & 24 & 43 \\
\hline 360 & 24 & 47 \\
\hline 361 & 16 & 22 \\
\hline 362 & 15 & 45 \\
\hline 363 & 15 & 22 \\
\hline 364 & 16 & 41 \\
\hline 365 & 15 & 42 \\
\hline 366 & 16 & 42 \\
\hline 367 & 15 & 45 \\
\hline 368 & 16 & 29 \\
\hline 369 & 16 & 32 \\
\hline 370 & 16 & 42 \\
\hline 371 & 16 & 42 \\
\hline 372 & 16 & 30 \\
\hline TOTAL: & & 931 \\
\hline
\end{tabular}

Gráfico 1. Elaboración propia. Fotografías publicadas por meses

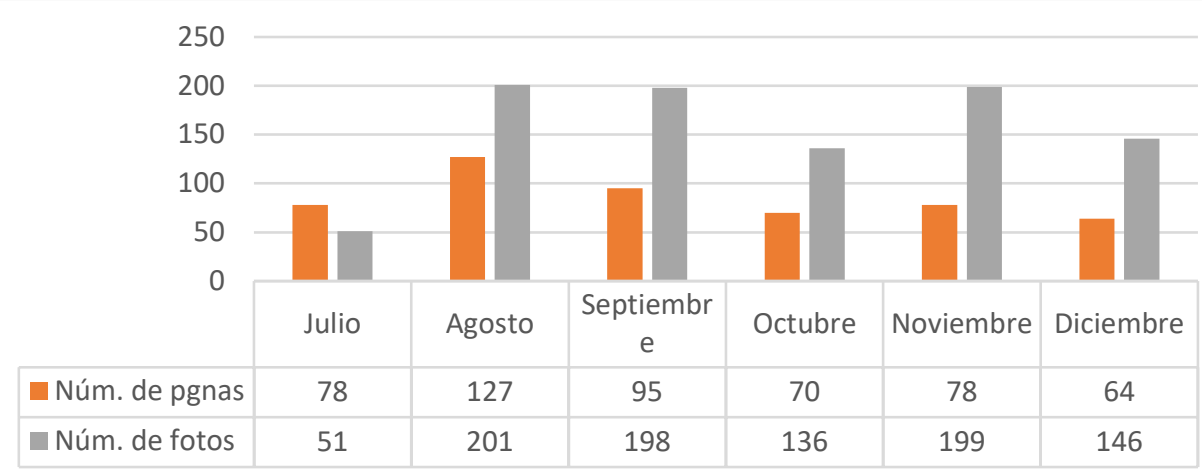

- Núm. de pgnas $\quad$ Núm. de fotos 
La justificación al mayor o menor grado de intensidad en la cubertura visual en función de los meses parece pasar por la propia evolución de la contienda. A medida que el gobierno republicano se sintió rodeado, parece publicar menos información y más imágenes. Pero, ¿qué tipo de instantáneas? Para ello, es necesario hacer un análisis de los tres espacios que se abrieron tras la sublevación de julio. Los datos son claros: de las 927 instantáneas publicadas en el primer año de guerra, Crónica tuvo un interés evidente por retratar el espacio de la retaguardia, con un total de 402 instantáneas, lo que supone un $43.17 \%$. Le sigue el retrato en el frente con 303 fotografías (un 32.54\%) y en la retaguardia militar con 215 fotografías (23.09\%). Residual es mostrar las instantáneas que retratan algún aspecto de la guerra tomadas en el exterior -como un barco extranjero navegando en aguas internacionales pero que participa en el conflicto español, o una delegación política de España en el extranjero, por poner dos ejemploscon 11 imágenes, un 1.18\% del total (Gráfico 2).

Gráfico 2. Elaboración propia. Fotografías publicadas por meses y espacios

\begin{tabular}{|c|c|c|c|c|c|c|}
\hline 120 & & & & & & \\
\hline \multicolumn{7}{|l|}{100} \\
\hline \multicolumn{7}{|l|}{80} \\
\hline \multicolumn{7}{|l|}{60} \\
\hline \multicolumn{7}{|l|}{40} \\
\hline \multicolumn{7}{|l|}{20} \\
\hline \multirow[t]{2}{*}{0} & & & & & & \\
\hline & Julio & Agosto & $\begin{array}{c}\text { Septiembr } \\
\text { e }\end{array}$ & Octubre & Noviembre & Diciembre \\
\hline Frente & 17 & 92 & 47 & 35 & 58 & 53 \\
\hline Internacional & 0 & 1 & 8 & 2 & 0 & 0 \\
\hline Retaguardia & 0 & 56 & 96 & 77 & 102 & 70 \\
\hline Retaguardia Militar & 34 & 52 & 47 & 22 & 36 & 23 \\
\hline
\end{tabular}

En relación con nuestra hipótesis, si atendemos a los meses en los que disminuye el papel pero aumenta el número de instantáneas, observamos que hay un protagonismo creciente de la retaguardia sobre el frente. De las instantáneas que se publicaron en los tres primeros meses de contienda (julio, agosto y septiembre), 156 tuvieron como protagonista el frente, 133 la retaguardia militar y 152 la retaguardia (no hemos tenido en cuenta las 9 instantáneas tomadas en un espacio extranjero). Estos datos, si se traducen en porcentajes, dan como resultado un $35.37 \%$ en el frente, $30.15 \%$ en la retaguardia militar y $34.92 \%$ en la retaguardia. Sin embargo, si analizamos los datos de los meses de octubre, noviembre y diciembre, periodo que coincide con las primeras derrotas importantes de la guerra, el resultado es 146 instantáneas en el frente -en este punto debemos aclarar que la mayoría de las instantáneas tomadas en el frente y que se publicaron en el mes de diciembre son escenas de asueto, entretenimiento y 
abastecimiento en la primera línea coincidiendo con el periodo de la Navidad y no escenas bélicas-, 81 en la retaguardia militar y 249 en la retaguardia, lo que supone un $30.67 \%$, 17.01\% y 52.31\%, respectivamente. La conclusión: se aprecia un decreciente interés por el frente $\mathrm{y}$, sobre todo, por la retaguardia militar (concretamente en instantáneas sobre el alistamiento y formación de tropas), y un aumento del protagonismo de las fotografías que inmortalizan la retaguardia.

Por otro lado, la mayoría de las imágenes están tomadas en la ciudad de Madrid y el frente de Madrid. Un total de 540 (lo que supone un 58\% del total), aunque también se cubrieron otros espacios, siguiendo los sucesos y acontecimientos a modo de crónica visual de la guerra. Sobre todo, Barcelona y Valencia. Es decir, el semanal Crónica hizo un mayor seguimiento a las ciudades que fueron sede del gobierno republicano. De Madrid se publicaron 205 instantáneas del frente (22.01\%), 113 de la Retaguardia Militar (12.13\%) y 222 de la Retaguardia (23.84\%), frente a las 3 del frente de Barcelona (0.32\%), 81 de la retaguardia militar (8.7\%) y 57 de la retaguardia (6.12), y de Valencia 7 del frente (0.75\%), 11 de la retaguardia militar (1.18\%) y 90 de la retaguardia, lo que supone un 9.66 (Gráfico 3).

Gráfico 3. Elaboración propia. Fotografías publicadas por espacios y zonas

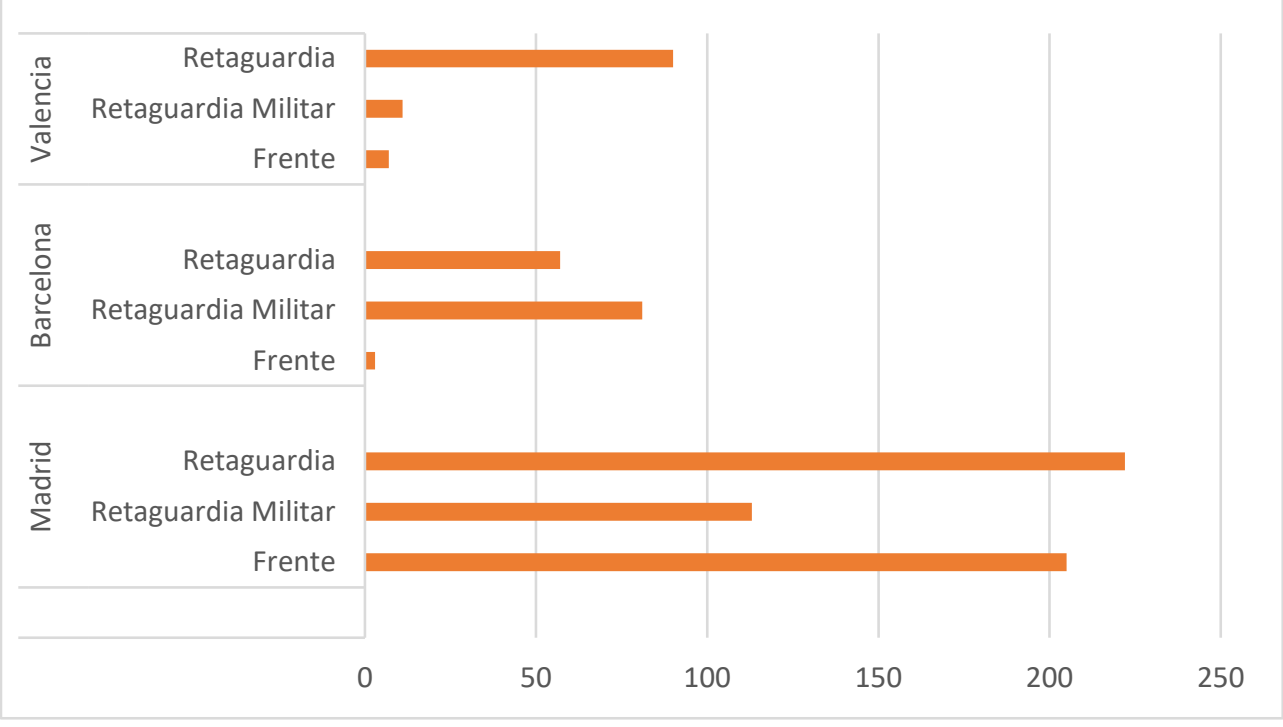

Si centramos nuestra mirada sobre la autoría, son 48 los sellos que constan en las páginas del semanal, aunque hay que advertir algunos detalles. En ocasiones, el sello recoge el trabajo de un colectivo que, además, se presenta con varios nombres. Es el caso, por ejemplo, de Santos Yubero y los Hermanos Benítez Casaux que firman sus trabajos individuales como "Santos Yubero" y "Benítez Casaux", y los conjuntos de dos formas diferentes: "Benitez Yubero" y "Santos Yubero Benítez". A este total, habría que sumar las 67 fotografías anónimas (7.19\%). Además, debemos añadir las 3 imágenes que se recuperaron del archivo de "Prensa Gráfica” (tomadas en Francia, 
la U.R.S.S. y U.S.A.) (lo que supone un 0.32\%) y las 5 instantáneas de agencias extranjeras (0.53\%): 3 tomadas en Francia de "Foto Press", "Meurisse" y "Trampus", y 2 tomadas en Suiza y firmadas por la agencia "Mondial” y "Voir" (Tabla 2).

Teniendo en cuenta los datos, destaca el trabajo que para Crónica realizaron “Albero y Segovia” con 101 instantáneas-un 10.84\% del total-, Torrents con un 140 a las que hay que sumar 5 publicadas como artísticas -un $15.57 \%$ del total- y Videa, con 219 instantáneas, lo que supone un 25.52\%.

Tabla 2. Elaboración propia. Fotografías publicadas con respecto a la autoría

\begin{tabular}{|l|c|}
\hline \multicolumn{1}{|c|}{ Fotógrafo } & $\begin{array}{c}\text { Núm. De } \\
\text { fotos }\end{array}$ \\
\hline Albero y Segovia & 101 \\
\hline Álvaro & 22 \\
\hline Anónima & 67 \\
\hline Antifafot Madrid & 7 \\
\hline Archivo Prensa Gráfica & 3 \\
\hline Baldomero & 6 \\
\hline Barea & 1 \\
\hline Benítez Casaux & 3 \\
\hline Benítez Yubero & 6 \\
\hline Canales & 2 \\
\hline Canales Marí & 1 \\
\hline Cervera & 4 \\
\hline Cortés & 2 \\
\hline Cosconela & 1 \\
\hline C.R.A & 1 \\
\hline Díaz Casariego & 2 \\
\hline Dondía Valls & 1 \\
\hline Espiga & 7 \\
\hline Finezas & 4 \\
\hline Foto H.A. & 5 \\
\hline Foto Press & 1 \\
\hline Galán & 3 \\
\hline García & 7 \\
\hline García Benedito & 2 \\
\hline Lázaro & 4 \\
\hline
\end{tabular}

\begin{tabular}{|l|c|}
\hline \multicolumn{1}{|c|}{ Fotógrafo } & Núm. De fotos \\
\hline Luis Vidal & 18 \\
\hline Luis Vidal y Vidal Corrella & 10 \\
\hline Mayo & 6 \\
\hline Merletti & 6 \\
\hline Merletti Hijo & 9 \\
\hline Meurisse & 1 \\
\hline Mondial & 1 \\
\hline Montaña & 8 \\
\hline Oples & 1 \\
\hline Pando & 23 \\
\hline Pando y Piortiz & 3 \\
\hline Piortiz & 35 \\
\hline S. Gonzalo & 6 \\
\hline Sáez & 1 \\
\hline Santos Yubero & 45 \\
\hline Santos Yubero Benítez & 40 \\
\hline Torrents & 140 \\
\hline Torrents Arte & 5 \\
\hline Trampus & 1 \\
\hline Vidal & 36 \\
\hline Vidal Corrella & 42 \\
\hline Vidal Corrella y Vidal & 7 \\
\hline Videa & 219 \\
\hline Videa y Piortiz & 4 \\
\hline Voir & 1 \\
\hline
\end{tabular}

\section{La poética visual de Crónica. Información y estrategia}

Una vez establecido el perfil cuantitativo de la colección, es el momento de abordar cuestiones que tienen que ver con la interpretación de los datos extraídos en el estudio anterior. Giran en torno a tres conceptos que, aunque no se analizan en profundidad, se presentan: información, estrategia y poética. Estos tres elementos definen los rasgos más importantes de las instantáneas que se publicaron en Crónica durante la Guerra Civil Española. Lo haremos con ejemplos visuales. 
Debemos empezar señalando el poder de la fotografía en dos momentos históricos separados por el tiempo: presente y futuro. El presente representa el momento del lector primero -es decir, el ciudadano que vivió la guerra en el año 1936- y el futuro -nuestro tiempo presente- el de la lectura visual que realizamos más de 80 años después. En el primero, la fotografía se presenta como fuente de información para el lector y como un soporte estratégico de comunicación para la autoridad. En la actualidad, se ha convertido en memoria que nos aporta una información reveladora sobre el contexto histórico.

La fotografía es un fragmento de espacio y tiempo, por lo que es una referencia al "allí" (es decir, tiene una dimensión espacial) y al "entonces" (es decir, tiene una dimensión temporal). De esta manera, es un rastro (precisamente por mostrarnos un lugar y un momento) y también un resto, ya que se ha materializado en placa o negativo y, por tanto, patrimonio que debe ser conservado.

Y como es un rastro, se puede considerar un certificado: algo ocurrió ante la cámara del fotógrafo y lo hizo de una forma determinada. Esta constatación visual, que está en la naturaleza de la instantánea, es uno de los usos estratégicos habituales de la fotografía en un periodo bélico: la que sirve de prueba de absolución o incriminatoria. Pongamos un ejemplo. El 2 de agosto de 1936 se publicó en Crónica un reportaje sobre el desarrollo del conflicto en el frente de la sierra norte de Madrid. Se acompañó de una fotografía firmada por Albero y Segovia que pretendía servir de denuncia. En la imagen se muestra la fachada del Hospital de Sangre de Buitrago de Lozoya, claramente identificado por la bandera ondeante de Cruz Roja, en la que se aprecian daños por metralla. Se acompaña del pie: "Este Hospital ha sido bombardeado por la aviación rebelde, contrariamente a las leyes de la guerra y a los principios de Humanidad”. En esta ocasión queda clara la utilización estratégica de la fotografía como testimonio de los ataques del enemigo contra espacios protegidos. Y es que Crónica reveló la gran capacidad informativa y estratégica a las instantáneas. La propaganda fue un arma más de la guerra y su empleo exigió un cuidado máximo, tal y como se reflexionó en La Voz del combatiente (9 de enero de 1937: 3): "Una de las armas más a nuestro favor con que contamos para ganar la guerra es precisamente la propaganda; de ahí que nos valgamos de ella con tacto, con mesura, con verdadero tino, y no confundamos su propia finalidad". En el mismo artículo se denunció la falta de profesionalidad y se reivindicó la necesaria profesionalización en su uso: "un arma llamada a deshacer entuertos no los siga creando de la manera más lamentable por la impreparación de quienes ni saben manejarla ni comprenden su alcance político”. Y esta profesionalización de la fotografía como táctica se basó en una triada propagandística: mantener la moral de los aliados, desacreditar al enemigo y, finalmente, convencer a externos de la necesidad de implicarse en un conflicto siempre presentando como el preludio de la II Guerra Mundial, siendo cuatro las estrategias visuales más empleadas durante este periodo: mostrar, ocultar, retener y reconducir (De las Heras, 2017).

Podríamos decir, además, que la fotografía, por ser un retal de espacio y tiempo, permite servirnos de ella como un testimonio para el presente. Captura algo que ha ocurrido pero que no ha pasado gracias a su congelación en un soporte: un instante preciso de la realidad. Sobre esta capacidad ya reflexionó John Berger al comparar 
la fotografía con la memoria: “Ambos -se refiere a la fotografía y a lo recordadopreservan el momento y proponen su propia forma de simultaneidad, en la que todas las imágenes pueden coexistir. Ambos estimulan, y son estimulados por, la interconexión de los sucesos. Ambos buscan instantes de revelación, porque son sólo esos instantes los que dan la razón completa de su propia capacidad de resistir el flujo del tiempo" (Berger y Mohr, 1998: 280). Y esa cualidad de perpetuar un momento se muestra en esta instantánea de Albero y Segovia publicada en Crónica el 9 de agosto de 1936 (Figura 3), en la que se puede constatar la potencia de la fotografía como la conservación de un momento que pasa -que ha ocurrido-, pero que, gracias a la técnica, se mantiene vivo, nos traslada desde nuestro presente a un momento del pasado: justo el instante en el que dos aviones de la República destruyen una posición enemiga que vuela por los aires.

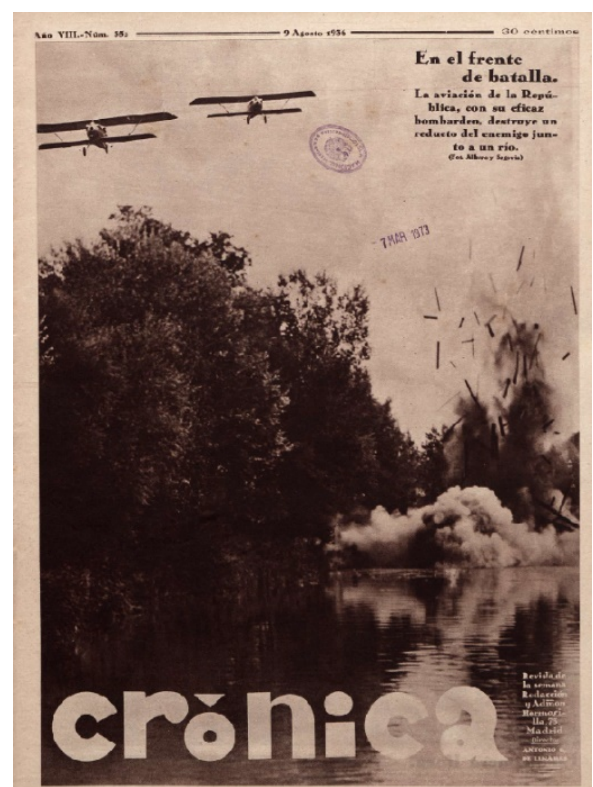

Figura 3. Fotografía de Albero y Segovia en Crónica, 9 de agosto de 1936

Al margen de estas referencias a la importancia de la fotografía como fuente de información, soporte para la estrategia, memoria del pasado y patrimonio, y centrando nuestra atención en las instantáneas publicadas en Crónica, podemos relacionar la colección con metáforas visual porque, pese a las circunstancias y priorizar, como es lógico en tiempos de guerra, la información, el semanario seleccionó, de entre las posibilidades, la fotografía simbólica. Siempre buscó el camino entre lo icónico y lo verbal, incluso en forma de juego hacia el lector visual. Rescatemos un ejemplo: en la portada y contraportada del 6 de diciembre de 1936 (Figura 4), abriendo y cerrando el número, se publicaron dos instantáneas en forma de retratos de un miliciano y una miliciana. El guiño al lector se encuentra dos números después cuando en el número del día 20 de diciembre, se publica un reportaje firmado por E.A. bajo el titular "Los cursos de urgencia en la Escuela 
Oficial de Enfermeras de la Generalidad de Cataluña”. El texto está acompañado de 4 fotografías que retratan a enfermeras del Sindicato Único de Sanidad de Cataluña. Están firmadas por Torrents, tal y como se detalla en el pie de una de las imágenes y en el cuerpo del artículo, en el que se menciona: "En las fotos que hace Torrents quedan grabadas las sonrisas de estas lindas muchachas, para embellecer la Revista y para que nuestros milicianos las contemplen pensando que, si caen heridos, ellas les cuidarán solícitamente”. En una de las instantáneas (Figura 5), tres jóvenes, posando, comparten la lectura de un ejemplar de la revista del día 6 de diciembre mostrando, de forma evidente, su portada y contraportada.
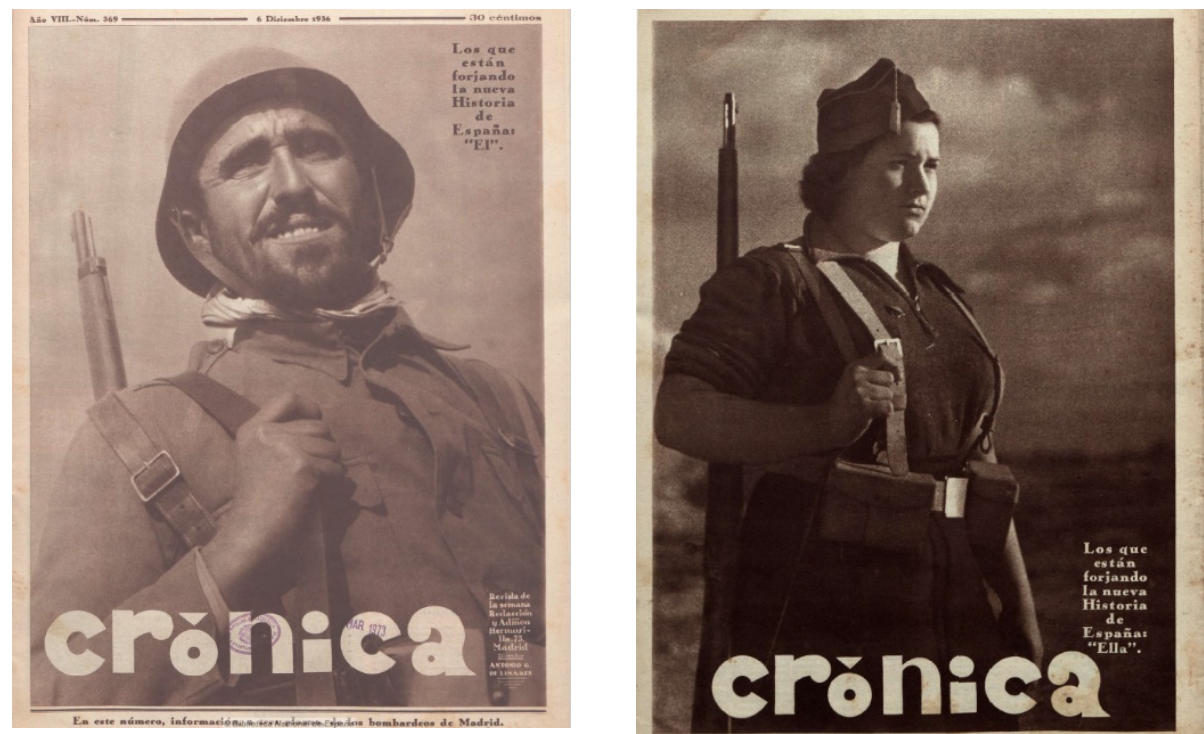

Figura 4. Fotografías en Crónica, 6 de diciembre de 1936

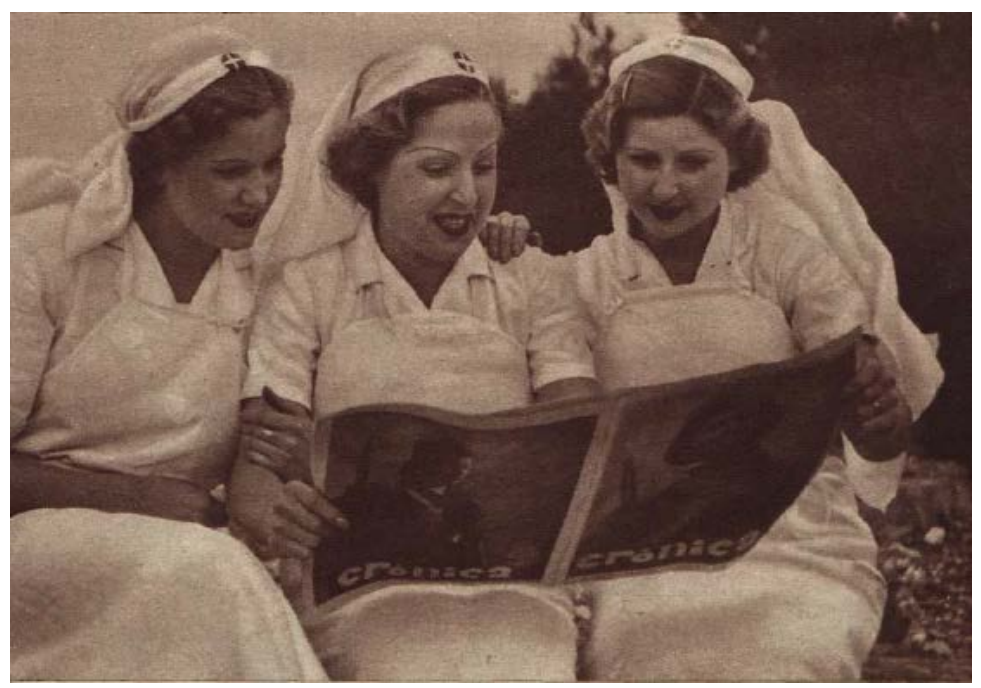

Figura 5. Fotografía de Torrents en Crónica, 20 de diciembre de 1936 
Aparte de esos guiños al lector que se presentan como goznes visuales, es indiscutible el interés tomado por el medio para seleccionar las imágenes que coparon portadas, contraportadas e imágenes interiores con un objetivo informativo, pero claramente estético, invariablemente desde el primero hasta el último número. Y todo a pesar de las dificultades. De las 40 páginas del primero de los números se pasó, progresivamente, a 8 páginas del último con, puntualmente, 4 páginas como el número del 10 de julio de 1938. A pesar de las circunstancias, la calidad de impresión y de las instantáneas se mantuvo, algo que se refleja, por ejemplo, en el cuidado por la acreditación de la autoría. Sólo 67 instantáneas que copan el semanario durante el primer año de guerra son anónimas, lo que denota el interés que se tomó la publicación por la fotografía y por el reconocimiento de la figura del reportero gráfico. Algo poco habitual en la época, momento en el que muchas de las instantáneas publicadas en prensa o que se conservan en archivos no están referidas. También se muestra esa disposición en la cuidada selección de imágenes, desde la primera hasta la última página. En las portadas de Crónica, como en el caso del diario $A B C$, se cede el protagonismo a toda página cuidando, especialmente, la calidad, composición y el significado metafórico de la instantánea elegida, incluso priorizando el valor visual de portada sobre la ilustración de un hecho noticioso, algo que es más común, como es lógico, en los semanarios que en los diarios en los que se prima la última hora.

De hecho, y como ya hemos mencionado, la preocupación constante por parte de Crónica de hacer constar la autoría revela la importancia de la imagen, no como una mera ilustración que acompaña la noticia, sino como un fin en sí mismo. Como muestra, recuperamos la portada del número del 30 de agosto de 1936 (Figura 6), dedicada al trabajo de las mujeres voluntarias en el cuidado de los heridos de guerra. Se trata de un trabajo de Videa en la ciudad de Madrid. La búsqueda del gesto en el primer plano, la composición de los actantes en la que el protagonismo es para la enfermera y el "héroe" queda delicadamente oculto por la mano de ella para que el lector, independientemente de quien sea, se identifique o identifique a un tercero, la selección que hace que la cabecera del diario encaje a la perfección, la luz, el marco, ... La escena se cuida al detalle. No se trata de una fotografía más de guerra.

Cabe destacar, también, que, como ocurre en Estampa -revista hermana-, las contraportadas de Crónica siempre fueron artísticas cediendo el protagonismo a una fotografía -aunque en algunos casos, muy puntuales, se recoge una serie de instantáneas- o dibujo a toda página, y no a un anuncio, como era habitual en otros medios. En el caso de las fotografías, siempre se presentan como alegoría o metáfora visual, como en el trabajo de P. Lluis Torrents publicado el 15 de noviembre de 1936 (Figura 7), acompañado de la locución: “!Al combate!”. La revista eligió la imagen de una hilera de soldados que transita por un camino y de los que se destacan las botas y el fusil, mostrando milicianos sin rostro. Una estrategia de identificación con el combatiente que se empleó en carteles y cine documental, ya en la I Guerra Mundial. 


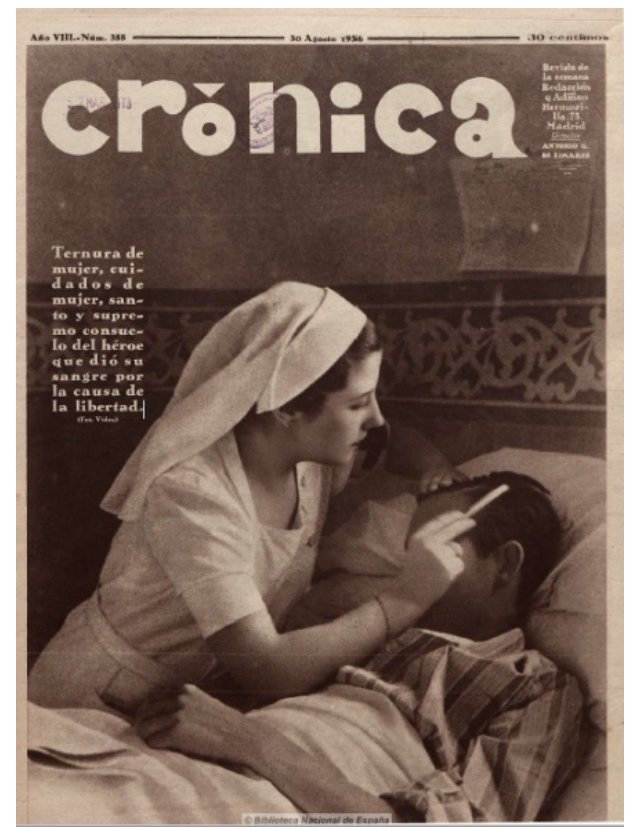

Figura 6. Fotografía de Videa en Crónica, 30 de agosto de 1936

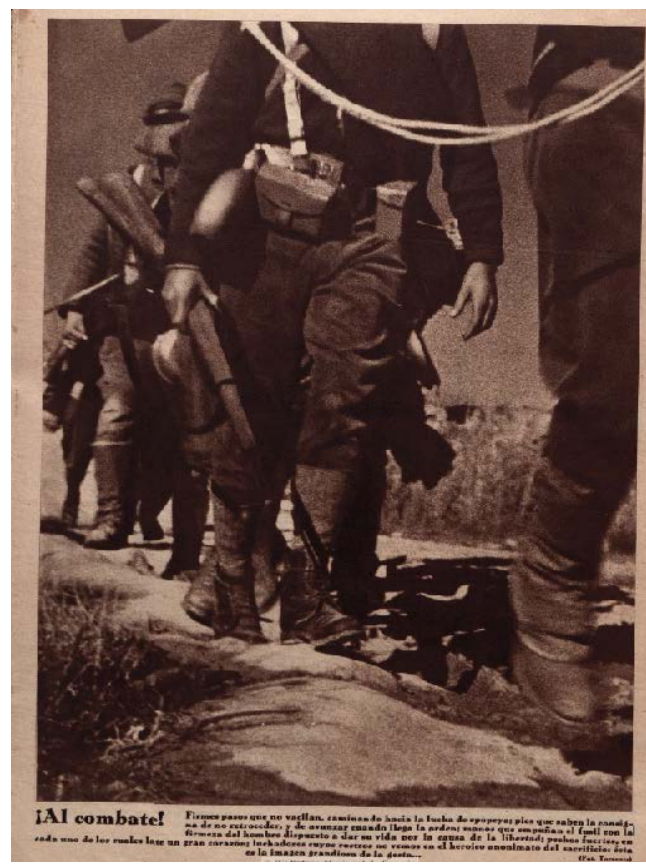

Figura 7. Fotografía de Torrents en Crónica, 15 de noviembre de 1936

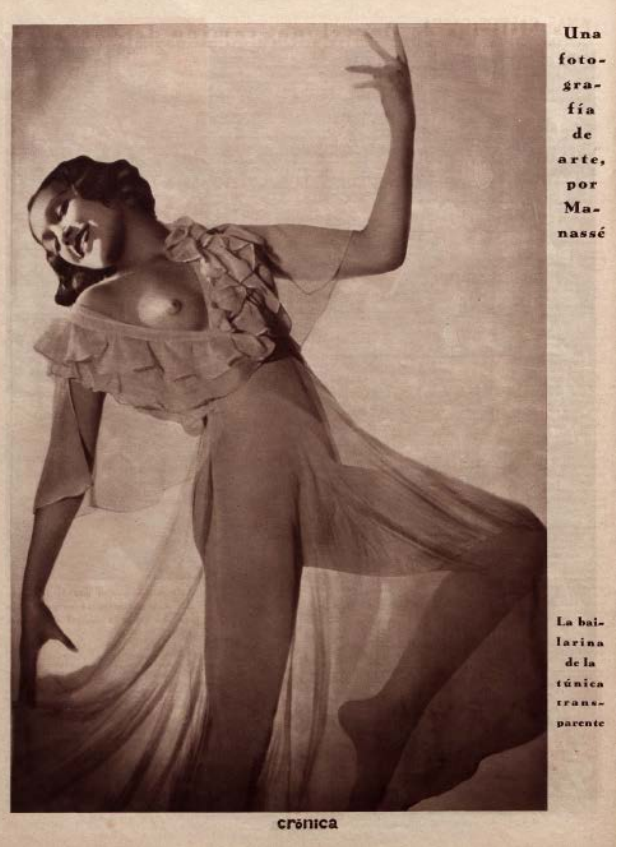

Figura 8. Fotografía de Manassé en Crónica, 2 de agosto de 1936 
Otra prueba de la atención prestada por la revista a las imágenes técnicas es que, incluso en los tiempos en los que se vivía, encontró espacio para la fotografía artística. Llamativa resulta la colección de imágenes que se publicó en los primeros meses, manteniendo el espíritu de sus inicios, de mujeres, tal y como se recogió en la página 22 del número del 2 de agosto de 1936 (Figura 8). Se trata de un trabajo de Manassé, en el que se retrata a una joven vestida con gasas. Se la presenta como "La bailarina de la túnica transparente”, y a la que se le ve un pecho. Al margen, también se publicaron fotografías artísticas sobre escenas cotidianas o de guerra, como las 5 firmadas por Torrents bajo el sello Torrents Arte el 20 de diciembre de 1936 (Figura 9) en las que se retrata el frente de Huesca bajo el titular: "La guerra, bajo un cielo de tormenta”. Aunque el trabajo de fotógrafo siempre fue de gran calidad, es apreciable el tono artístico de estas imágenes.

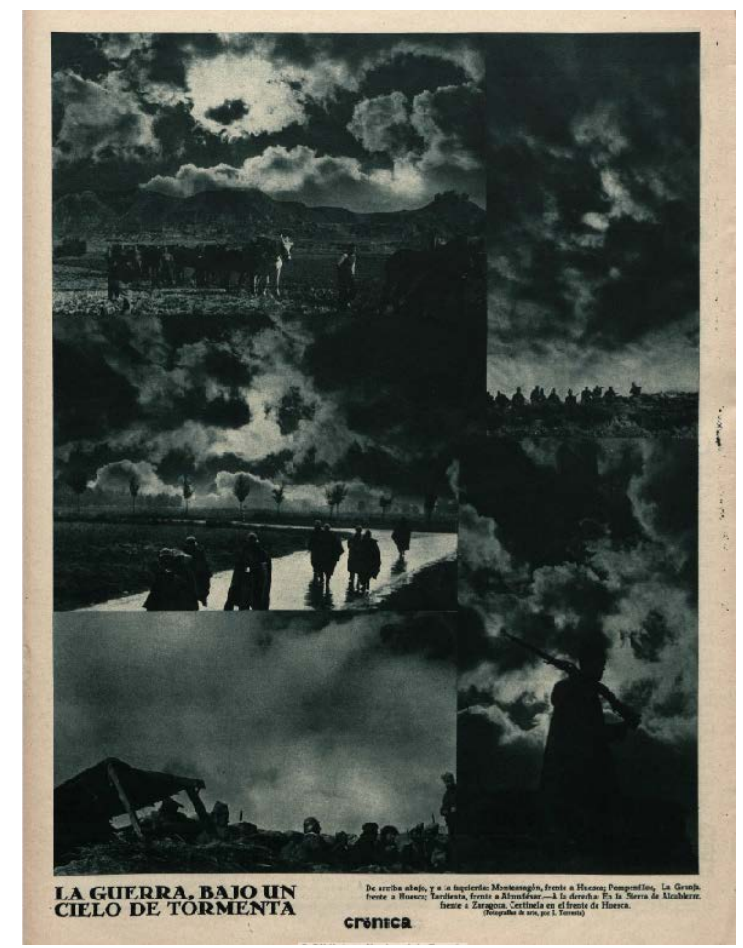

Figura 9. Fotografías de Torrents en Crónica, 20 de diciembre de 1936

\section{Conclusiones}

Una fotografía publicada en prensa durante un periodo de conflicto puede ser un medio y un fin en sí mismo. Medio porque es información y estrategia, y fin porque puede presentarse en forma de metáfora. Con el tiempo, esa imagen es memoria (ya que nos traslada a un espacio y tiempo, el que retrató) y patrimonio, porque ha generado una materialidad que debe ser conservada. $\mathrm{Y}$ estos cuatro aspectos se dan en las instantáneas publicadas en el semanario Crónica durante la Guerra Civil 
Española: son estrategia, metáfora, memoria y patrimonio. Y, por tanto, una fuente de incalculable valor para los historiadores.

Pero, ¿cómo convertir una fotografía en un testimonio del pasado y, por tanto, en material de trabajo para el historiador? Aplicando una mirada reflexiva basada en el escudriñamiento y evitando la superficialidad del análisis reivindicando, para ello, su superación como ilustración. Crear un discurso previo y encajar la instantánea en él no es emplear la fotografía como fuente de memoria. Y eso es lo que hemos proyectado en este trabajo. Tras elegir una colección -la correspondiente a las fotografías publicadas en Crónica durante el primer año de guerra-, y justificar su elección, catalogamos el material, transformamos los datos en cifras y creamos unos perfiles que nos permitirán, en un nuevo trabajo, la interpretación, última fase del análisis que debe realizarse.

\section{Referencias bibliográficas}

Gonzàlez Vilalt, A. (2019). La capsa vermella. Barcelona: Comanegra.

Aupí, V. (2017). Crónicas de fuego y nieve. Teruel: Dobleuve Comunicación.

Collier, J.; Collier, M. (1986). Visual Anthropology: Photography as a Research Method. Albuquerque: University of New Mexico Press.

Berger, J.; Mohr, J. (1998). Otra manera de contar, Murcia: Mestizo.

De las Heras, B. (2011). Fotografia e Historia. El testimonio de las imágenes. Madrid: Vincent Gabrielle.

De las Heras, B. (2017). Imágenes de y para una guerra. España, 1936-1939. Madrid: Síntesis. Foucault, M. (1970). La arqueología del saber. México: Siglo XXI.

Gómez Mompart, J. L.; Espinet, F.; Álvarez, J. T. (1990). Historia de los medios de comunicación en España. Periodismo, imagen y publicidad. Barcelona: Ariel Comunicació.

López Mondéjar, P. (2005). Historia de la Fotografía en España. Barcelona: Lunwerg.

Mainer, J. C. (2006). Años de víspera. La vida de la cultura en España (1931-1939). Madrid: Espasa.

Nash, M. (2006). Rojas, las mujeres republicanas. Madrid: Taurus.

Pérez Álvarez, Á.; Gómez Baceiredo, B.; Mártínez Illán, A. (2017). Los géneros retratísticos durante la II República española en las revistas Estampa y Crónica; (1931-1936): características de un género periodístico en auge. Estudios Sobre El Mensaje Periodístico, 23 (2), 1351-1368.

Pizarroso Quintero, A. (1997). La comunicación de masas en España y EE. UU. (1918-1936: panorama comparado. REDEN, 8 (14), 107-138.

La propaganda, como arma de guerra en La Voz del combatiente, 9, enero, 1937, p.3.

Rodríguez de las Heras, A. (2010). L'ús pedagògic de la fotografía histórica. Educació i História: Revista d'História de l'Educació, 15, 41-54

Rubido Pérez, A. (2020). Las cajas de Ámsterdam: Kati Horna y los anarquistas de la CNTFAI. Historia Social, 96, 21-40.

Sáiz, M. D..; Seoane, M. C. (1996). Historia del periodismo en España 3. El Siglo XX: 18981936. Madrid: Alianza.

Salvador Benítez, A. (2018). Fuentes fotográficas para el estudio de la guerra civil. Archivos, fondos y colecciones. Letra Internacional, 126, 33-64.

Sánchez Vigil, J. M. (2008). Revistas ilustradas en España. Del Romanticismo a la guerra civil. Gijón: Ediciones Trea, 
Sánchez Vigil, J. M.; Olivera Zaldua, M. (2014). Fotoperiodismo y República. Madrid: Cátedra.

Seoane, M. C.; Sainz, M. D. (2007). Cuatro siglos de periodismo en España. De los “avisos” a los periódicos digitales. Madrid: Alianza Editorial.

Szto, P.; Furman, R.; Langer, C. (2005). Poetry and Photography: An Exploration into Expressive/Creative Qualitative Research. Qualitative Social Work, 4 (2), 135-156.

Vera Casas, . (2005). Aproximació a la fotografía de reportatge en la revista Estampa (19281938). Universitat Jaume I, ed. El análisis de la imagen fotográfica. Actas del I Congreso Internacional de Teoría y Técnica de los Medios Audiovisuales, 306-321.

Artículo escrito en el marco del Proyecto de Investigación "Memória, Património e Construção de Identidades” (FCT:uID4059) del Centro de Investigação e Memória de la Universidade do Porto y del Proyecto de Investigación "Vocabularios para una red de archivos y colecciones de Media Art y sus efectos: Metaliterancy y Turismo de conocimiento" (HAR2016-75949-C2-1-R) del Plan Estatal de Investigación Científica y Técnica y de Innovación de la Universidad Carlos III de Madrid. 